\title{
Programa para poner en valor de uso turístico atractivos del sistema cavernario del destino Gibara
}

Program to put in value of tourist use attractions of the cave system of the Gibara destination

Evelina Cardet Fernández. ${ }^{1}$, Daniela Denisis Batista Rodríguez. ${ }^{2}$ \& Manuel Menéndez Pérez ${ }^{3}$

\begin{abstract}
The development of the nature tourism modality and its adventure byproduct are currently a necessity for the country, since one of its aims is to expand and diversify the existing product portfolio. However, there are territories that present interesting attractions of this nature that have not yet been exploited. The Gibara municipality is one of the most beautiful in the Holguin province and has great speleotouristic potential. That is why, this research addresses from the aforementioned modality and its sustainability, to the particularities of speleotouristic practices, including cave diving and has aimed to design a program for the value of tourism use of the cave system in the destination Gibara. For this purpose, a methodology was made up of five phases, seventeen steps and whose application also allowed diagnosing the situation of the cave system, proposing work areas, indicators and strategies, as well as actions to achieve them; contributing to eradicate the main problems that directly affect the caves, while contributing to the enrichment of the tourist offer of the destination and to the dynamism of the life of the local inhabitants, in addition to generating opportunities for them.
\end{abstract}

Key Words: Nature Tourism, Speleotourism, Cave System

\section{Resumen}

El desarrollo de la modalidad de turismo de naturaleza y su subproducto de aventura, constituyen actualmente una necesidad para el país, puesto que uno de sus fines es lograr ampliar y diversificar la cartera de productos existente. Sin embargo, existen territorios que presentan interesantes atractivos de esta índole que aún no han sido explotados. El municipio Gibara, es uno de los más hermosos de la provincia Holguín y cuenta con un

\footnotetext{
${ }^{1}$ MsC. Universidad de Holguín, evelina@uho.edu.cu

${ }^{2}$ Lic. Complejo Turístico Gibara, nany777@ nauta.cu

${ }^{3}$ MsC. Centro de Capacitación para el Turismo de Holguín, manuel.menendez@ehtfr.tur.cu
} 
gran potencial espeleoturístico. Es por ello, que la presente investigación aborda la modalidad anteriormente mencionada y su sostenibilidad, las particularidades de las prácticas espeleo turísticas, incluyendo el buceo en cavernas y su objetivo ha sido diseñar un programa para la puesta en valor de uso turístico del sistema cavernario en el destino Gibara. Para ello fue confeccionada una metodología que consta de cinco fases, diecisiete pasos y cuya aplicación permitió además diagnosticar la situación del sistema cavernario, proponer ámbitos de trabajo, indicadores y estrategias, así como, acciones para lograrlas; contribuyendo a erradicar los principales problemas que afectan directamente a las cuevas y cavernas, a la vez que se contribuye al enriquecimiento de la oferta turística del destino y al dinamismo de la vida de los pobladores locales, además de generar oportunidades para ellos.

Palabras Clave: Turismo De Naturaleza, Espeleo turismo, Sistema Cavernario

\section{Introducción}

El turismo es una de las mayores actividades económicas del mundo, pues representa un tercio del valor total del comercio mundial de servicios. Los diversos beneficios directos e indirectos que genera, hacen que muchos países en desarrollo y con recursos turísticos potenciales, vean en el turismo una oportunidad para impulsar el desarrollo de muchas zonas marginales. A nivel internacional, según la Organización Mundial del Comercio (OMC, 2018) el turismo representa el 35\% de las exportaciones mundiales y más del 70\% en los países menos adelantados.

Actualmente, han crecido y se han diversificado los motivos por los que se decide realizar un viaje turístico, y a la vez, han surgido clientes cada vez más exigentes, que no solo se conforman con una experiencia basada en disfrutar junto a su familia o amigos en un lugar diferente al habitual, sino que las expectativas y deseos, se extrapolan a vivir algo diferente, que los exponga a una vivencia única e inigualable llena de emociones. Es por eso, que el turismo, se ha dinamizado y evolucionado en los últimos años, esto lo demuestra, el incremento en un 7\% de las llegadas de turistas internacionales en el 2017. En las Américas se recibieron 207 millones de turistas internacionales en el mismo año, y específicamente un aumento del 4\% en Centroamérica y el Caribe. (OMT, 2018)

Cuba, también es escenario del crecimiento turístico, principalmente en los dos últimos años. Las características del archipiélago cubano y la explotación de sus recursos turísticos propician este aceleramiento en las estadísticas turísticas, aunque todavía no se logra sobrepasar a la competencia.

La modalidad de sol y playa es el producto principal que comercializa Cuba, pero existen otros productos líderes, que atraen de igual forma un sustancial volumen de clientes, ejemplo de ello es el turismo de naturaleza.

Según Martínez-Quintana (2017), el turismo de naturaleza es la "frontera" de todos los turismos, y el punto inicial y final en los procesos experimentales del sector turístico. La materia principal es el patrimonio natural-cultural, y todos los beneficios y riquezas que se obtengan marcarán el éxito o el fracaso de esta industria. Si se destruye el medio 
ambiente y se altera la autenticidad de los destinos turísticos, se dispondrá de espacios desgastados, deshabitados y desestructurados, en los que la experiencia del disfrute del viaje y de la estancia pierda su significado y razón de ser.

Lo expresado anteriormente expone una de las principales tendencias o modalidades practicadas hoy en el mundo, el turismo de naturaleza se considera como uno de los principales tipos de turismo de más rápido crecimiento en el mundo, con tasas entre $25 \%$ y $30 \%$. (IDT, S/F)

La humanidad ha tomado conciencia con respecto a los severos problemas ambientales que se están desarrollando, y es por ello que, en su mayoría los viajeros de turismo de naturaleza compiten en la carrera por dejar menor huella ecológica en sus viajes, realizando actividades que privilegien el cuidado de la naturaleza y el medio ambiente. Por lo general, sus desplazamientos son motivados por "las características del destino, en donde cobran relevancia, factores tales como aprender sobre la naturaleza, la actividad física y reunirse con personas con el mismo interés". Este debe tener como principio y base la sostenibilidad, acompañado del disfrute y las actividades que en ella se realizan. (MCIT, 2012)

El Ministerio del Turismo de la República de Cuba (Mintur) ha decidido priorizar el turismo de naturaleza, debido fundamentalmente a tres aspectos (Medina, 2004): auge de las preocupaciones por el medio ambiente a nivel mundial, el potencial de Cuba para el desarrollo de esta modalidad y la necesidad de enriquecer el principal producto turístico (sol y playa) para complementar la oferta con los atractivos culturales y naturales de cada región.

La provincia Holguín, ubicada en el norte de la región oriental de Cuba, es una de las regiones priorizadas en el turismo. Aunque se dispone de una variada gama de recursos la oferta no los aprovecha suficientemente, por lo que necesita ser rejuvenecida, y el producto naturaleza es uno de los que pueden ser mayormente explotados, debido a su exuberante belleza y diversidad paisajística.

Holguín es un territorio con un potencial de productos turísticos que van más

allá de los ofertados por la modalidad de sol y playa, esto se reafirmó en el XI Evento Internacional de Turismo de Naturaleza TURNAT'2017, desarrollado en áreas del Oriente Norte de Cuba. (Veloz-Placencia, 2018)

El turismo de aventura es un sub-producto de la anterior modalidad, y dentro de este se encuentra el segmento especializado de espeleo turismo. A principios del siglo XIX, en Europa personas comunes y corrientes comienzan a explorar las cavernas cercanas a sus hogares y muy pronto a desplazarse más lejos para conocer otras cavidades, y es así como se le da comienzo al desarrollo de esta actividad tan demandada actualmente.

No obstante, a que, según el diccionario enciclopédico Larousse, una cueva es un sótano o cavidad de la tierra, natural o artificial y una caverna es una concavidad natural muy profunda en la tierra o en las rocas (Larousse, 2006), en la literatura especializada se 
utilizan indistintamente los términos cueva y caverna para referirse a las mencionadas cavidades.

El espeleo turismo son todas las actividades que se realizan con fines recreativos y de observación dentro de cuevas o sótanos, grutas y cavernas, incluso en las que se encuentren inundadas se puede desarrollar un espeleobuceo controlado, una de las actividades con más riesgos dentro del espeleo turismo.

La ciudad de Gibara, o como también se le conoce: La Villa Blanca de los Cangrejos, tiene una población de 38534 habitantes y una extensión territorial de $630 \mathrm{~km}^{2}$, distribuidos en 15 asentamientos, entre los que destacan: la ciudad capital Gibara, con más de 16.000 habitantes; Velasco, Floro Pérez, Uñas, Playa Caletones y Playa Los Bajos. (Anuario Estadístico de Cuba, 2018)

Gibara, es uno de los municipios de la provincia Holguín con mayor cantidad y diversidad de atractivos turísticos, recientemente, lanzada como destino turístico en la pasada Feria Internacional del Turismo, FIT Cuba 2017, lo cual implica que exista un aceleramiento en la explotación y puesta en valor de sus atractivos.

El destino Gibara, posee recursos exclusivos para el desarrollo del turismo náutico y de buceo, destacándose el sistema cavernario de alto valor para el espeleo turismo donde resalta Tanques Azules, la mayor caverna inundada de Cuba poseedora de una indescriptible belleza subacuática (Cardet-Fernández, 2017).

En el Primer Evento Internacional sobre Biodiversidad y Turismo, presentaron el potencial espeleo turístico que posee la provincia Holguín, incluyendo destacadamente el destino turístico Gibara (Guarch-Rodríguez y Pérez-Iglesias, 1998). Lo que se reafirma nuevamente por (Casals-Corella y Corella Varona, 2006) quienes reiteran el valor espeleo turístico del municipio Gibara y el conjunto de formaciones cavernarias inundadas del mismo, que le posibilitarán la práctica de un turismo especializado de espeleo turismo. También se hace alusión al tema en el Primer Taller de Turismo de Naturaleza en Áreas Protegidas y Silvestres Región Holguín (Martínez-Pérez, 2013). Además, durante los días del Taller de Diversidad Biológica y Turismo, Biotur 2018, que con el auspicio de Ecotur, se desarrolló en Gibara, con el fin de promocionarlo como destino turístico entre las distintas agencias de viajes del país, como Gaviotatur, Cubatur, Havanatur, Cubanacán, entre otras, también se defendieron las posibilidades y oportunidades que presenta el mismo para el desarrollo de un turismo especializado mediante la explotación de su sistema cavernario. Entre las actividades propuestas para el desarrollo del evento estaban las visitas a la cueva Los Panaderos y la caverna Tanques Azules. Como resultado de la satisfacción obtenida en este último encuentro, se acaba de aprobar por el Mintur, que la edición 2019 del mismo se desarrolle de igual forma en el destino Gibará, lo que favorecerá aún más el desarrollo turístico del territorio. (Pichs-Rodríguez, 2018)

Debido al creciente desarrollo que se ha evidenciado a lo largo del tiempo en esta modalidad y la necesidad de su explotación de forma sostenible, Cuba aprueba la Resolución Conjunta No.1 del 19 de mayo de 1999, que regula la autorización comercial para el desarrollo del turismo de naturaleza, a través de la explotación de senderos, 
caminatas y recorridos en el territorio nacional y legaliza los 116 productos de esta modalidad turística que se venían comercializando desde el año 1998. (Mintur-CITMAMinag, 1999)

La Resolución No. 50 de 2014 del Mintur, establece los principios y procedimientos para la aprobación de los productos turísticos de naturaleza, aventura y rural en el territorio nacional. En específico, dentro de las áreas protegidas y sus zonas de uso público, constituyó el punto de partida para el reordenamiento de la actividad.

De igual forma, los Lineamientos 207 y 208 de la política económica y social del Partido y la Revolución para el periodo 2016-2021, aprobados en el 7mo Congreso del Partido en abril de 2017 y por la Asamblea Nacional del Poder Popular en junio de 2017 (PCC, 2017), ratifican la necesidad de diversificar la oferta turística. El banco de problemas para el período 2016-2020 del Centro de Capacitación del Turismo Holguín, Universidad de Holguín y Centros de Investigación del CITMA hacen referencia a la insuficiente diversificación y diferenciación de la oferta turística del destino en cuanto a la modalidad turismo de naturaleza y sus derivados.

\section{Metodología}

\section{Metodología para el diseño del programa para la puesta en valor de uso turístico de los atractivos asociados al sistema cavernario del destino gibara}

Se parte de considerar que el espeleo turismo es la modalidad que supone todas las actividades que se realizan dentro de cavernas o cuevas turísticas, sin fines científicos, sino con el objetivo de disfrutar y conocer de las diferentes formaciones que se producen en la oscuridad que las caracteriza, al igual que de su fauna y flora.

Así mismo, se considera que las cavernas o cuevas turísticas, no son más que aquellas cavidades subterráneas que han sido debidamente adecuadas para su uso turístico, a fin de garantizar la seguridad y satisfacción del visitante, así como la protección y conservación de la cavidad en sus niveles físicos, químicos y biológicos. Es decir, son aquellas cuevas abiertas al público en general, y a las que se puede acceder sin necesidad de usar equipamiento especializado. Normalmente tienen caminos, verjas, luz eléctrica, guías turísticos y suele ser necesario pagar una cuota para poder entrar.

Teniendo en cuenta las definiciones anteriores y luego de una exhaustiva revisión bibliográfica que permitió consultar múltiples investigaciones tanto a nivel nacional como internacional, relativas a diseño de programas o planes de manejo de áreas protegidas, recreación y turismo en reservas de la biosfera, programas de ecoturismo de parques nacionales, entre otras; se tomó como base el procedimiento propuesto por Peña (2016) y se confeccionó la metodología para el diseño del programa para la puesta en valor de uso turístico de los atractivos asociados al sistema cavernario del destino Gibara que consta de cinco fases e incluye diecisiete pasos, tal y como se muestra en la figura 1. 

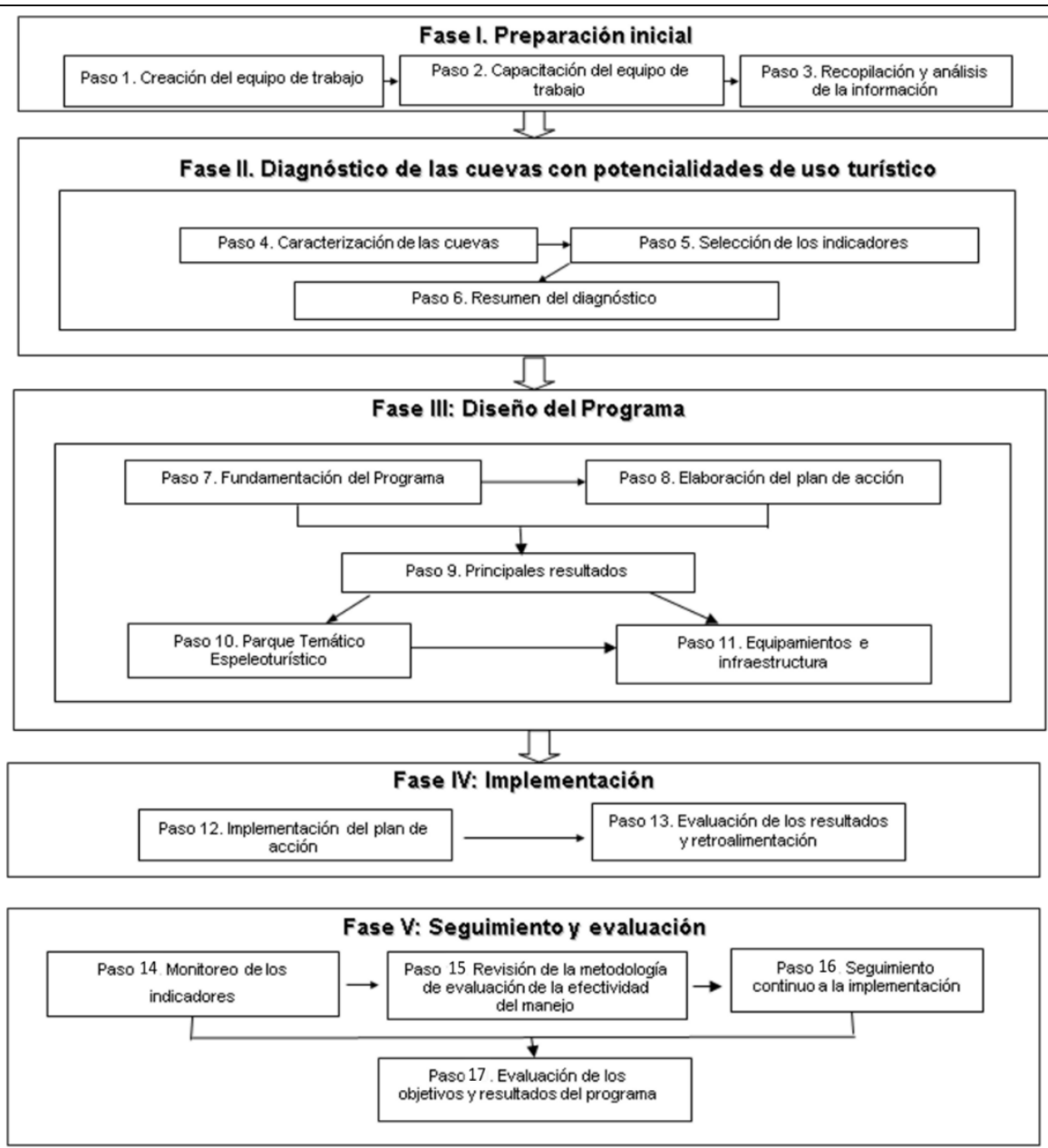

Figura 1. Metodología para el diseño del programa para la puesta en valor de uso turístico de los atractivos asociados al sistema cavernario del destino Gibara

Se realizó una aplicación parcial de la metodología diseñada, lo cual implicó la creación de un equipo integrado por nueve especialistas graduados de nivel superior o medio superior, con cinco años o más de experiencia profesional, conocimientos relacionados con el sistema cavernario del destino y sobre el diseño y desarrollo de programas turísticos. Los especialistas fueron capacitados a través de talleres, principalmente dirigidos a la actualización profesional de los mismos, con respecto a las características que presentan las cavidades y a las legislaciones vigentes sobre el manejo de las mismas.

Luego se realizó la recopilación y análisis de la información sobre el sistema cavernario del destino Gibara, que cuenta con numerosas cavidades interesantes desde el punto de vista espeleológico y paisajístico, pues posee un carst muy característico de esa zona formado esencialmente por la circulación hídrica subterránea, sin que hayan intervenido en estos procesos corrientes superficiales. Las formas endocársticas son muy notables existiendo numerosas dolinas, poljes y extensos campos de lapiéz.

$\mathrm{Al}$ analizar las distintas características morfológicas, geológicas, genéticas y carstológica de la región, Gibara se subdivide en seis sectores, tal y como se muestra en la figura 2. 


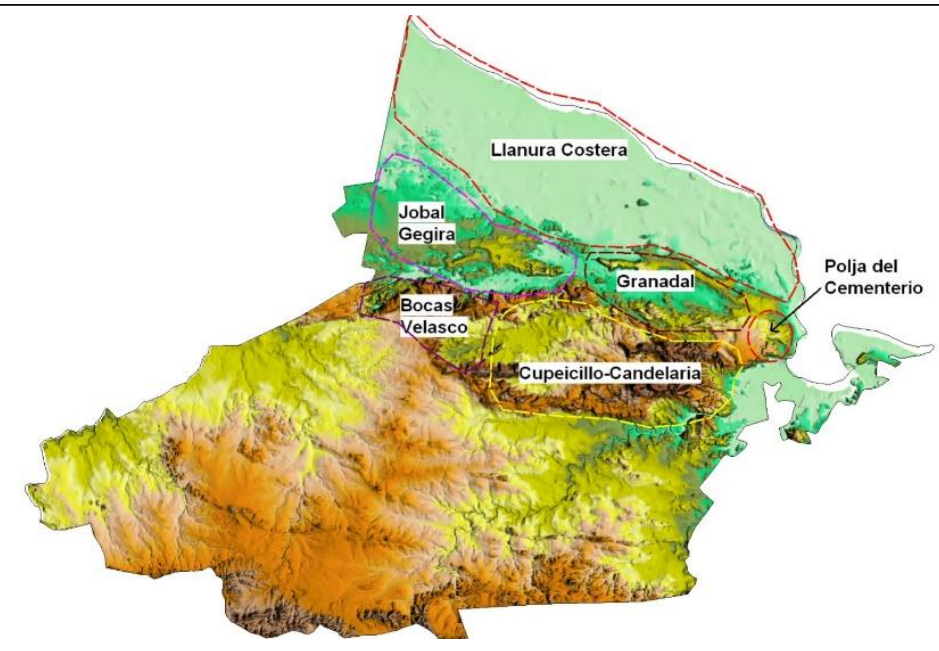

Figura 2: Los sectores del karst de Gibara

Fuente: Gibara en busca de un tesoro. Nápoles-Cabrera, Adriana (2019)

Sector llanura costera: Formada por una extensa llanura costera kárstica en la que la mayoría de las cavernas son de origen freático, se hallan completamente inundadas y poseen generalmente un solo nivel de galerías.

Sector Granadal: Constituido mayoritariamente por sistemas de terrazas marinas y la mayor parte de las cavidades son de origen freático, poseyendo en muchos casos lagos activos en sus sectores más profundos. Generalmente tienen dos niveles de galerías bastante rectilíneas, comunicados por pequeños resaltes.

Sector Cupeicillo-Candelaria: Aquí se encuentran las alturas de la Sierra de Candelaria y Cupeicillo, elevaciones erosivas y patrogénicas que conservan huellas de antiguas terrazas marinas que representan un complejo horst asimétrico constituido por bloques de caliza, dolomita y brechas calcarias, en los que se ha desarrollado un intenso karst. Las cuevas que más abundan son las de origen vadoso y están constituidas por conductos verticales.

Sector Jobal-La Gegira: Se desarrolla en parte sobre el macizo Cupeicillo en su porción más occidental y sobre un curioso sistema de poljes longitudinales de fondos cóncavos, cuya disposición areal y posiciones escalonadas reflejan su origen, en una red de valles antiguos fuertemente karstificados. La mayor parte de las cavidades son freáticas, con pisos horizontales y pequeños pozos que comunican unos niveles con otros.

Sector Polje del Cementerio: Formado por un interesante polje, en cuyo fondo se abren las mayores cavidades de toda la región de Gibara, que constituyen un sistema cavernario con un desarrollo total cartografiado de $11000 \mathrm{~m}$. La mayor parte de las cavernas son de origen freático y en ellas se forman 7 niveles de galerías, estando el inferior ocupado por las aguas freáticas que constituyen lagos medianos intercomunicados entre sí por medio de sifones o bóvedas sifonantes.

Sector Bocas-Velasco: Formado por dos paisajes muy diferentes desde el punto de vista geomorfológico. El primero está constituido por la porción Oeste de la Sierra de Candelaria y el segundo por un gran polje que separa la mencionada sierra de las Lomas 
de Cupeicillo. El fondo de dicho Polje está constituido por grandes extensiones de roca estructural, parcialmente cubierta por depósitos terrígenos, que desciende escalonadamente hasta la altura de 30 m s.n.m.

Seguidamente se realiza el diagnóstico del estado actual de los atractivos asociados a las cavernas en el destino Gibara, el cual facilitó la caracterización de las formaciones cársicas con potencialidades para su puesta en valor como cuevas turísticas, sustentada en investigaciones desarrolladas aproximadamente en los últimos veinte años. Fueron identificadas cinco formaciones con posibilidades de explotación de forma inmediata, estas son:

Caverna inundada Tanques Azules: Ubicada en las cercanías de la playa Caletones, es la mayor caverna inundada de Cuba con $3225 \mathrm{~m}$ de desarrollo total, sus aguas, de una transparencia asombrosa mantienen una temperatura promedio de $24^{\circ} \mathrm{C}$ y en ellas existe una variada fauna acuática entre la que se pueden encontrar peces ciegos, crustáceos y anguilas, entre otros animales. Destaca la amplitud de los salones y galerías, que permiten fácilmente transitar por ellos sin levantar sedimento de los pisos cavernarios, evitándose de esta forma el desagradable fenómeno de la turbidez de las aguas, por lo que estas siempre se mantienen cristalinas y con una visibilidad de más de $20 \mathrm{~m}$.

Cueva Los Panaderos: Se encuentra ubicada en el sector polja del cementerio, en cuyo fondo se abren las mayores cavidades de toda la región de Gibara, que constituyen un Sistema Cavernario con un desarrollo total cartografiado de $11000 \mathrm{~m}$. En su interior se pueden encontrar lagos medianos intercomunicados entre sí por medio de sifones o bóvedas sifonantes. Además, en su interior se encuentran diferentes manifestaciones de fauna y flora.

Cueva La Fuente: Se ubica en la Sierra de Candelaria, aproximadamente a dos kilómetros al norte-noroeste del poblado de Tumbadero y el acceso hasta ella es relativamente fácil pues es a través de un camino que conduce desde el poblado hasta la entrada de la misma. Posee 1200 m de extensión, la más extensa de la Sierra de Candelaria, de la cual pueden ser visitados unos $400 \mathrm{~m}$ correspondiendo estos a los más bellos de la cavidad. Presenta un pequeño lago que le da nombre a la caverna y mantiene el agua hasta en épocas de sequía.

Cueva de La Masanga: Se encuentra ubicada en las Lomas de Cupeicillo, en la ladera Este de estas elevaciones, frente a la llanura costera que se extiende hasta la bahía de Gibara. Se trata de una pequeña cueva de unos $80 \mathrm{~m}$ de recorrido total, su piso es plano no presentando desniveles y la mayor parte de ella se halla iluminada por el sol, ya que presenta numerosas claraboyas. Sus mayores atractivos, se refieren a las cuestiones arqueológicas y paleontológicas, por la existencia de manifestaciones de convivencia de los aborígenes con el megalocnus rodens, el mayor mamífero que existió en Cuba, por lo que está planteado un museo arqueológico-paleontológico.

Caverna El Fructuoso: Una de las cavidades más importantes del sector cársico JobalGegira, la cual se encuentra ubicada a $700 \mathrm{~m}$ al noroeste del poblado El Jobal. Cuenta con una superficie aproximadamente de $820 \mathrm{~m}$, un amplio lago de aguas puras y 
cristalinas, donde viven conjuntamente camarones y peces propiamente cavernícolas, junto a peces de habitad dulceacuícola como los gupis y otras especies parecidas.

En el siguiente paso, se seleccionan los indicadores para diagnosticar y evaluar el estado actual del sistema cavernario en el destino Gibara, los cuales permiten determinar los aspectos principales que limitan y entorpecen la puesta en valor de uso turístico de las mismas. El sistema de indicadores se propone sobre la base de las tres dimensiones para el desarrollo sostenible de un destino turístico, establecida por la OMT: ambiental, económica y sociocultural y añadiendo una cuarta denominada institucional, con el fin de dejar plasmadas las regulaciones y aspectos necesarios para establecer límites para la explotación turística en las cavernas.

En la tabla 1 se presenta el sistema de indicadores para el programa de puesta en valor del sistema cavernario en el destino Gibara.

Tabla 1 Sistema de indicadores para el programa de puesta en valor del sistema cavernario en el destino Gibara

Institucional

Estatus legal del área

Infraestructura necesaria para el desarrollo de la actividad turística

Personal adecuado para el desempeño de la actividad turística dentro de las cuevas

Equipos y herramientas necesarios para la actividad

Coordinación entre instituciones para su puesta en valor
Ambiental

Calidad ambiental del aire, la atmósfera y la ventilación

Cuidado y conservación de la fauna y la flora existente en las cuevas

Gestión de residuos sólidos

Gestión de residuos líquidos

Calidad de las aguas

Regulación para la explotación turística

\section{Sociocultural}

\section{Económico}

\section{Participación comunitaria}

\section{Vías de financiamiento}

Beneficio en las organizaciones del entorno

Financiamiento necesario para la puesta en valor

Relación con los actores internos y la población Inversiones ambientales

Uso de nuevas tecnologías

Expectativas de los consumidores 
Una vez aplicado el sistema de indicadores a cada una de las cavernas antes descritas y por cada una de las dimensiones mencionadas, se concluye que, en la totalidad de las cuevas, las dimensiones más afectadas son: la ambiental y la institucional respectivamente, sin embargo, en el resto de los ámbitos se señala que la incapacidad de manejo del presupuesto es el problema que mayormente afecta la dimensión económica. Por otro lado, la totalidad de los especialistas consultados afirma que las cuevas más afectadas por la comunidad son: la caverna Tanques Azules y la cueva Los Panaderos.

A partir de los resultados del diagnóstico y tomando como base la información que se obtuvo en el paso de análisis y recopilación de la información, se pasa al diseño del programa propiamente dicho, en el cual se identifican 4 ámbitos de trabajo a los que corresponden 4 objetivos específicos y 12 estrategias para las cuales han sido propuestas un total de 51 actividades.

\section{Fundamentación del Programa}

El sistema cavernario del destino Gibara, por su belleza, endemismo e incluso complejidad, presenta suficientes atractivos para el desarrollo de una práctica turística especializada, donde se mezclen un conjunto de sensaciones y vivencias que puedan convertir la visita, en un momento inigualable y lleno de magia, solo basta crear las condiciones necesarias para su explotación, y unirlas a lo único y autóctono que caracteriza a estas cavidades, acompañado también de una hermosa naturaleza circundante, historia y tradición. Por ello resulta importante plantear un programa que recoja las medidas necesarias para la puesta en valor de uso turístico de estas cavidades.

\section{Principales problemas identificados}

- Insuficiente señalización en los senderos hacia las cuevas y en el interior de las mismas

- Falta de protección e infraestructura en las cuevas

- Acceso ilegal a las cuevas

- Existencia de Guías ilegales

- $\quad$ No se aplica la legislación ambiental de las cavidades

- No se realiza inspección ambiental estatal a las áreas

- Incapacidad de manejo del presupuesto

- Ocurrencia de incendios

- Desechos sólidos y líquidos

- Falta una integración coherente entre los distintos gestores de las cavidades en el territorio

Objetivo general: Organizar y mejorar las condiciones actuales en las que se encuentra el sistema cavernario en el destino Gibara, para el desarrollo del espeleo turismo de forma sostenible, logrando la compatibilidad de estas actividades y la preservación de los valores naturales, históricos y culturales.

\section{Objetivos específicos}




\section{Ámbito institucional:}

Lograr alta compatibilización y consolidación entre los implicados y responsables de las cuevas en el destino Gibara, con el fin de garantizar las condiciones óptimas para su explotación.

\section{Ámbito ambiental:}

Estimular el cuidado y la protección del Medio Ambiente y concientizar a los visitantes y comunidad de las repercusiones y consecuencias que trae consigo el descuido del entorno.

\section{Ámbito sociocultural:}

Estrechar el vínculo con la comunidad en el proceso de conservación de los recursos y valores naturales del entorno en que se encuentra y como segmento de apoyo para la realización de las actividades de aseguramiento que demanda la modalidad.

\section{Ámbito económico:}

Prever y gestionar todas las vías de financiamiento y formas de obtención de presupuesto para lograr la puesta en valor de uso turístico del sistema cavernario en el destino Gibara.

\section{Formulación de estrategias}

Para cada uno de los ámbitos definidos fueron establecidas las correspondientes estrategias.

\section{Ámbito Institucional}

- Estrategia 1: Compatibilizar a todos los niveles las cuevas seleccionadas para su puesta en valor de uso turístico y presentarlas para su aprobación al Comité Ejecutivo del Consejo de Ministros (CECM) y Empresa Forestal Integral de Holguín.

- Estrategia 2: Crear o adecuar infraestructuras y equipamiento en función del uso público para elevar la calidad de la experiencia de los visitantes en las cuevas.

- Estrategia 3: Garantizar el recurso humano necesario, distinguido por su aptitud y actitud hacia el desarrollo del turismo sostenible y todas sus áreas vinculantes.

- Estrategia 4: Coordinar las responsabilidades específicas a las que debe responder cada organización implicada en la explotación turística de las cuevas.

- Estrategia 5: Garantizar el equipamiento y herramientas necesarias con la tecnología adecuada para la realización de las actividades espeleo turísticas.

\section{Ámbito Ambiental}

- Estrategia 1: Implementar mecanismos administrativos y sistemas de monitoreo ambiental y de visitantes, que aseguren una operación eficiente, funcionamiento de los ecosistemas, calidad de la experiencia, del recurso, de los servicios turísticos que responda a la corrección de las ineficiencias 
- Estrategia 2: Desarrollar acciones que minimicen la contaminación del aire, agua y suelo y la generación de residuos por parte de la empresa turística, los visitantes y la comunidad.

- Ámbito Sociocultural

- Estrategia 1: Integrar y empoderar a las comunidades locales y otros actores públicos y privados en la planificación y la toma de decisiones acerca del manejo y el futuro desarrollo del turismo en las cuevas.

- Estrategia 2: Implementar acciones educativas y de interpretación y divulgación ambiental en las comunidades.

\section{Ámbito Económico}

- Estrategia 1: Garantizar la capacidad de manejo contable-financiero institucional que asegure el control interno, la autogestión y la búsqueda de una distribución amplia y justa de los beneficios económicos y sociales resultantes de la actividad turística en las cuevas.

- Estrategia 2: Implementar encadenamientos productivos con el sector no estatal dirigidos a la dinamización de la actividad turística y la diversificación de las fuentes de empleo.

- Estrategia 3: Diseñar estrategias y actividades de comercialización y promoción que contribuyan a la comunicación de las nuevas ofertas y a la generación de ingresos.

Para cada una de las estrategias definidas por ámbitos, fueron propuestas las acciones a realizar para su consecución, las fechas de cumplimiento y los responsables del mismo; así como, la prioridad de cada acción. Por ejemplo, el cumplimiento de la Estrategia 3 del Ámbito Económico, presupone la realización de las actividades siguientes:

\begin{tabular}{|c|c|c|c|}
\hline Acciones & Prioridad & $\begin{array}{c}\text { Año de } \\
\text { ejecución }\end{array}$ & Responsables \\
\hline $\begin{array}{l}\text { Destinar presupuesto a } \\
\text { actividades de comercialización } \\
\text { y promoción }\end{array}$ & 1 & $2019-2020$ & $\begin{array}{l}\text { Empresa } \\
\text { Forestal } \\
\text { Integral de } \\
\text { Holguín }\end{array}$ \\
\hline $\begin{array}{l}\text { Diseñar trípticos que recojan la } \\
\text { totalidad de las cuevas } \\
\text { propuestas con sus principales } \\
\text { características y atractivos }\end{array}$ & 1 & 2020 & $\begin{array}{l}\text { Empresa } \\
\text { Forestal } \\
\text { Integral de } \\
\text { Holguín, } \\
\text { AAVV del } \\
\text { destino } \\
\text { Holguín }\end{array}$ \\
\hline $\begin{array}{l}\text { Diseñar posters u afiches que } \\
\text { promocionen al destino Gibara } \\
\text { con sus atractivos espeleos } \\
\text { turísticos }\end{array}$ & 1 & $2020-2021$ & $\begin{array}{l}\text { Empresa } \\
\text { Forestal } \\
\text { Integral de } \\
\text { Holguín }\end{array}$ \\
\hline
\end{tabular}




\begin{tabular}{llll}
\hline $\begin{array}{l}\text { Diseñar vallas que incluyan } \\
\text { imágenes de las cuevas del } \\
\text { destino Gibara }\end{array}$ & 1 & 2020-2021 & Empresa \\
& & Forestal \\
Integral de \\
$\begin{array}{l}\text { Proponer la inclusión de las } \\
\text { cuevas en los videos }\end{array}$ & 1 & 2021 & Holguín \\
promocionales del destino & & & Empresa \\
Holguín y de Cuba & & & Forestal \\
\end{tabular}

\section{Resultados}

Una vez implementado el programa se espera obtener los siguientes resultados:

1. Alto estándar y uso de tecnologías en las infraestructuras y equipamientos para el desarrollo de las actividades espeleo turísticas en las cuevas turísticas del destino

2. Entendimiento y disponibilidad entre los actores y decisores implicados en la explotación de las cuevas

3. Participación del sector privado en la implementación de cadenas productivas, para la dinamización de la actividad turística y diversificación de las fuentes de empleo

4. Manejo efectivo del presupuesto asignado para la explotación de las cuevas

5. Concientización ambiental de los visitantes, operadores turísticos, trabajadores de las cuevas y comunidades locales como resultado de implementar acciones de educación, interpretación y divulgación ambiental

6. Disminución de delitos y hechos que afectan la integridad de las cuevas como resultado de implementar los planes de protección y reducción de desastres.

El estudio realizado demuestra que el destino Gibara presenta condiciones óptimas para que se desarrolle un turismo especializado de eco aventuras, con énfasis en el espeleo turismo y espeleobuceo, basados en la sostenibilidad turística, de ahí que se proponga, además, un nuevo producto turístico: Parque Temático Espeleo turístico, como parte del cual se realizarán múltiples actividades que responden a las mencionadas modalidades.

El Parque Temático Espeleo turístico tendrá los siguientes objetivos:

- Ampliar y diversificar la oferta turística del destino Gibara.

- Lograr preferencia con respecto a los productos de los competidores.

- Incrementar los ingresos y utilidades del sector turístico en Gibara.

- Satisfacer la demanda de los turistas nacionales e internacionales.

- Responder a la política de desarrollo del Mintur para el período comprendido del 2016 al 2030 y a los Lineamientos del PCC.

La idea principal es contribuir a la diversificación de la oferta turística del destino Gibara, aprovechando las potencialidades que para el desarrollo del turismo de naturaleza se presentan en la localidad, en lo cual resultan de especial atractivo las actividades espeleo 
turísticas posibles de desarrollar, recreando temáticamente cada espacio disponible para la puesta en práctica de las mencionadas actividades.

Se proponen las siguientes ideas para el diseño del Parque Temático Espeleo turístico:

- Diseño de un punto de información localizado en el centro de la ciudad de Gibara, con el objetivo de que los visitantes que deseen realizar un recorrido por el destino puedan informarse sobre lo que ofrece el producto.

- Diseño de un centro de espeleobuceo, que incluya aulas especializadas para el desarrollo de actividades científicas y la impartición de cursos de buceo, ambientadas con imágenes de las cavernas Tanques Azules y El Fructuoso respectivamente.

- Diseño de un centro de espeleología para el impulso del estudio e investigación del karst de Gibara con el fin de propiciar el cuidado y protección del mismo, continuar la actividad investigativa realizada hasta el momento y fomentar las expediciones científicas en este sentido, las que cada vez más resultan de interés para segmentos de mercado específicos.

- Intercambios en el ámbito de las expediciones científicas, tanto a nivel nacional como internacional, por lo que el centro de espeleología incluirá una sala de reuniones.

Se considerará, además, la existencia de lugares de restauración y recreación tematizados desde su diseño exterior e interior hasta el de sus servicios con las cuevas del destino. Para el alojamiento se propone utilizar el nivel habitacional actual y perspectivo con que cuenta el Complejo Turístico Gibara. El sector no estatal tiene un papel determinante, por lo que se utilizará como apoyo para el desarrollo de las actividades antes mencionadas, dígase restauración, alojamiento y transporte.

Dentro del Parque Temático, se propone la realización de las siguientes actividades:

Espeleo turismo en la Cueva Los Panaderos: recorrido por todo el interior de la cueva hasta donde está permitido su acceso, realizando la observación de las diferentes formaciones cársicas y geológicas, además de otras actividades como el rapel.

Espeleobuceo en Tanques Azules: Recorrido exterior, que debe hacerse a pie acompañado de caballos en los que se transportarán los medios de buceo. Durante el mismo se podrán observar especies de plantas propias de las zonas cársicas costeras y aves, además de la observación de diversas formaciones cársicas superficiales, como campos de lapiéz, dolinas, etc. La parte final del recorrido y al mismo tiempo la más importante, se corresponde con la Caverna de Tanque Azul (la más extensa de las inundaciones de Cuba), y en ella se podrán observar galerías, salones, formaciones secundarias, etc., todo sumergido en las aguas; también se podrán ver ejemplares de la fauna avícola acuática.

Espeleobuceo en El Fructuoso: Se propone vincular esta actividad con el turismo rural, realizando un recorrido en tractor con carreta, utilizando medios de transporte del sector no estatal, hasta llegar al poblado cercano a la caverna. Mostrar a los visitantes la vida de 
los campesinos y los sembrados de plátanos que allí se encuentran y su forma de cultivo en piedras huecas. Luego, se realizará el espeleobuceo en la caverna.

Visita a la Cueva La Masanga: Traslado en jeep hasta las cercanías de la cueva, recorrido en el interior de la misma decorada con su historia paleontológica y geológica, explicando al visitante la convivencia que existió allí entre los aborígenes y el megalocnus rodens.

Visita a la Cueva La Fuente: el trayecto hasta la cueva se realizará a pie, donde se podrán observar fenómenos cársicos superficiales de gran magnitud como campos de lapiéz gigantes, grandes dolinas, grietas, etc.; también la avifauna como tocororos, sinsontes, zunzunes, cartacubas, etc., así como numerosas especies de plantas propias de los bosques semideciduos. También se podrá observar el desarrollo de la agricultura en estos terrenos cársicos, un aspecto típico del lugar, y elementos relacionados con la historia, pues se podrá visitar la Capitanía del $4^{\circ}$ Frente Oriental Simón Bolívar, ubicada en el área. En la segunda parte del trayecto (subterránea) se podrán observar innumerables espeleo temas del mundo subterráneo y se ofrecerán explicaciones sobre el origen de tales fenómenos. También se podrá ver parte de la fauna de estos recintos.

Finalmente, se proponen, además, productos complementarios para desarrollar a corto, mediano y largo plazo, los cuales se exponen en la figura 3.

Para todos los productos propuestos fueron identificadas las necesidades de materiales, herramientas y equipamiento requeridos para la puesta en valor de uso turístico de las cuevas, es decir, se identifica la infraestructura necesaria que deberá construirse o instalarse, de la cual destacan:

- Accesos

- Pasarelas en el interior de las cuevas

- Iluminación artificial con luces de tipo LEDs en el interior de las cuevas

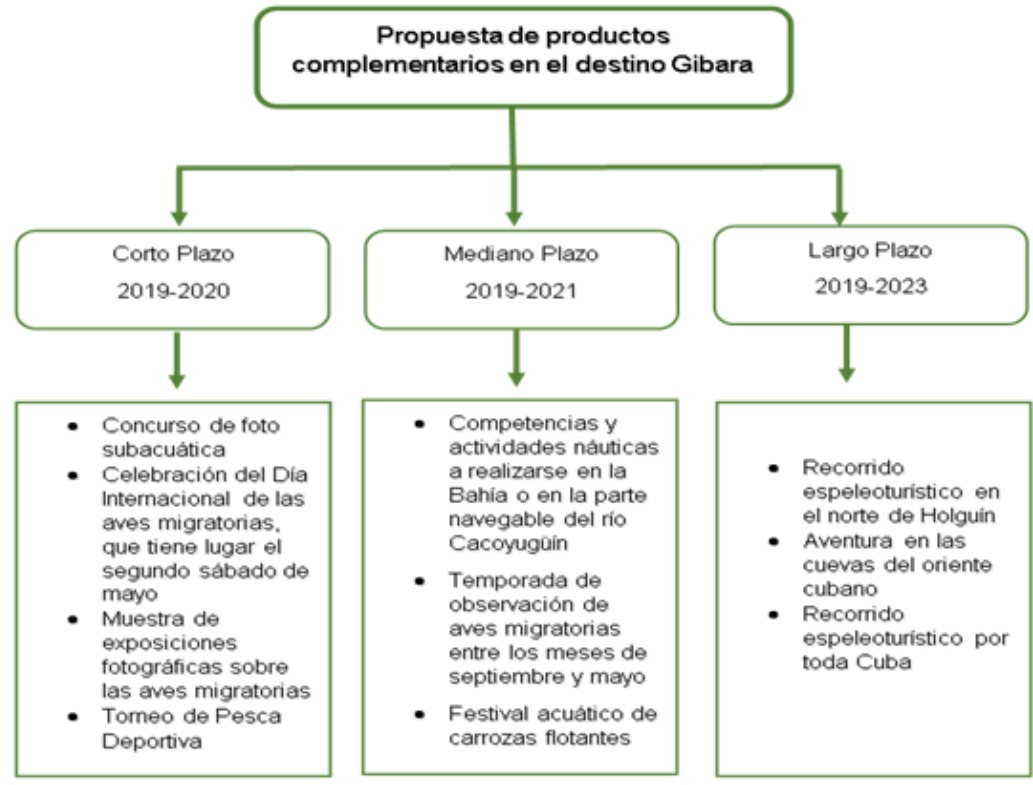

Figura 3: Propuesta de productos turísticos en el destino Gibara 
Valoración de la pertinencia del programa para la puesta en valor de uso turístico de las cuevas del destino gibara

Finalmente se realiza la evaluación de la pertinencia y relevancia del procedimiento, el programa y los indicadores propuestos, según criterio de especialistas y empleando herramientas informáticas, estadísticas y matrices. Los expertos consultados plantearon que:

- La metodología propuesta para el diseño del programa, tiene relevancia y utilidad pues el índice de evaluación es de 4,452 lo que corrobora que las diferentes fases y pasos propuestos son pertinentes; no proponiéndose modificaciones, inclusiones ni exclusiones a la dicha metodología.

- El programa propuesto es de importancia y susceptible de aplicar pues, el índice es de 4,442; no proponiéndose modificaciones, inclusiones ni exclusiones al programa.

- Los ámbitos e indicadores que se proponen para la evaluación de la efectividad del manejo durante la implementación del programa, se dictaminan como relevante y útil pues el índice es de 4,547.

La investigación realizada permitió proponer el programa para la puesta en valor de uso turístico de los atractivos asociados a las cavernas en el destino Gibara, partiendo de identificar los principales problemas que impiden su explotación turística, y a partir de ello se plantearon acciones para la misma, contribuyendo igualmente al enriquecimiento de la oferta turística del destino y al dinamismo de la vida de los pobladores locales, además de generar oportunidades para ellos.

\section{Conclusiones}

El cumplimiento del objetivo general de la presente investigación, así como la elaboración y aplicación de un programa para la puesta en valor de uso turístico del sistema cavernario del destino Gibara, ha permitido arribar a las conclusiones siguientes:

- El tema desarrollado es pertinente, debido a que la línea de investigación de la misma, se encuentra en conformidad con lo planteado en los Lineamientos 207 y 208 de la política económica y social del Partido y la Revolución para el periodo 2016-2021, aprobados en el 7mo Congreso del Partido en abril de 2017 y por la Asamblea Nacional del Poder Popular en julio de 2017.

- El espeleo turismo como actividad turística dentro del turismo de aventura, constituye un tema actual con mucho auge y demanda a nivel a nivel mundial, sin embargo, todavía en Cuba, situándose en el destino Gibara, no se aprovechan al máximo los recursos y potencialidades que presentan para el desarrollo de esta modalidad de forma sostenible.

- La selección y diseño de los indicadores utilizados en la investigación, propició contar con una herramienta metodológica que permitiera el desarrollo del diagnóstico en el sistema cavernario del destino Gibara y la evaluación de la 
efectividad del programa diseñado para la puesta en valor de uso turístico del mismo.

- Se diseñó un programa para lograr explotar turísticamente las cuevas seleccionadas, que una vez cumplido, contribuirá a la diversificación de la oferta de productos espeleo turísticos del destino Gibará en particular y de Holguín en general.

\section{Referencias bibliográficas}

Cardet-Fernández, E., Clarke-Bloomfield, M. \& Puente-Fernández, E. (2017, 16-19 mayo). El producto turístico territorial, una contribución al desarrollo local: el caso de Gibara. Paper presented at the Congreso Internacional de Desarrollo Local. Universidad de Oriente. Santiago de Cuba.

Casals-Corella, C., \& Corella-Varona, J. (2006, 25-27 octubre). Un viaje a través de nuestro litoral. Potencial natural de Gibara, Holguín. Paper presented at the Primer Evento Internacional sobre Biodiversidad y Turismo BIOTUR'2006, Hotel Pernik, Holguín. Cuba.

Diccionario enciclopédico (2006). El Pequeño Larousse Ilustrado. México D.F.: Ediciones Larousse S.A.

Guarch-Rodríguez, J. J., \& Pérez-Iglesia, L. (1998, 26-28 octubre). Potencial espeleoturístico de la provincia de Holguín, Cuba. Paper presented at the Primer Evento Internacional sobre Biodiversidad y Turismo BIOTUR'98, Playa Esmeralda, Holguín. Cuba.

Instituto Distrital de Turismo (IDT) (S/F). Turismo de naturaleza. Descargado de: http://www.bogotaturismo.gov.co/Turismo\%20de\%20Naturaleza.

Martínez-Pérez, R. (2013 diciembre, $1^{\circ}$ ). Turismo de Naturaleza en Áreas Protegidas y Silvestres en Holguín. Periódico Ahora! Descargado de: http://holguinahora.blogspot.com/2013/12/turismo-de-naturaleza-en-areas.html.

Martínez-Quintana, V. (2017). El turismo de naturaleza: un producto turístico sostenible. Revista Arbor: Ciencia, pensamiento y cultura, 193 (785), (1-14).

Medina-Pérez, N., \& Santamaría-Guerra, J. (2004). Turismo de naturaleza en Cuba. Ciudad de La Habana: Ediciones Unión.

Ministerio de Comercio Industria y Turismo (MCIT). (2012). Política de Turismo de Naturaleza. Bogotá: Documento preliminar. Colombia

Ministerio de Turismo-CITMA-Ministerio de la Agricultura. (1999). Resolución Conjunta No. 1-99. 
Ministerio de Turismo. (2014). Resolución No. 50: Principios y procedimientos para la aprobación de los productos turísticos de naturaleza, de aventuras y rural en el territorio nacional. Publicada en la Gaceta Oficial de Cuba

Nápoles-Cabrera, A. (2019). Gibara: en busca de un tesoro. Descargado de: http://webcache.googleusercontent.com/search?q=cache:kARcOTIQmIcJ:www. aldia.cu/es/fotoreportajes/3964-gibara-en-busca-de-untesoro $+\& \mathrm{~cd}=8 \& \mathrm{hl}=\mathrm{es} \& \mathrm{ct}=\mathrm{clnk} \& \mathrm{gl}=\mathrm{cu}$.

Oficina Nacional de Estadísticas e Información (2019). Anuario Estadístico de Cuba 2018. Capítulo 3: Población. Edición 2019. (s. 1.): ONEI.

Organización Mundial del Comercio. (2019). Examen estadístico del comercio mundial 2018 . http://www.wto.org/spanish/res_s/statis_s/wts2018_s/wts18_toc_s.htm.

Organización Mundial del Turismo. (2018). Resultados del turismo internacional en 2017: los más altos en siete años. Descargado de: https://www.unwto.org/es/press-release/2018-01-15/resultados-del-turismointernacional-en-2017-los-mas-altos-en-siete-anos.

Partido Comunista de Cuba. (2017). Documentos del 7mo. Congreso del Partido. La Habana, Cuba: Tabloides I y II. La Habana: UEB Gráfica Empresa de Periódicos.

Peña-Peña, N. (2016). Programa de Gestión Ambiental para el desarrollo del turismo sostenible en el Sistema Provincial de áreas Protegidas, Holguín. Tesis en opción al título de Máster en Ciencias en Gestión Ambiental, Facultad de Economía, Universidad de Holguín,

Pichs-Rodríguez, L. (2018 julio, 18). Desarrollarán Taller BIOTUR 2018 en Holguín los días 19 y 20. Periódico Ahora! Descargado de: http://www.ahora.cu/es/holguin/2384-desarrollaran-taller-biotur-2018-enholguin-los-dias-19-y-20.

Veloz-Placencia, G. (2018 marzo, 9). Más allá del turismo de sol y mar. Periódico Granma digital. Descargado de: http://www.granma.cu/cuba/2018-03-09/masalla-del-turismo-de-sol-y-mar-09-03-2018-20-03-31.

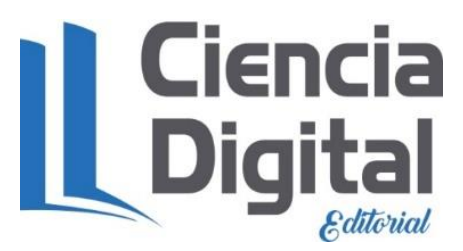




\section{PARA CITAR EL ARTÍCULO INDEXADO.}

Cardet Fernández, E., Batista Rodríguez, D. D., \& Menéndez Pérez, M. (2021). Programa para poner en valor de uso turístico atractivos del sistema cavernario del destino Gibara. Explorador Digital, 5(1), 244-262. https://doi.org/10.33262/exploradordigital.v5i1.1501

\section{¿Ciencia}

El artículo que se publica es de exclusiva responsabilidad de los autores y no necesariamente reflejan el pensamiento de la Revista Explorador Digital.

El artículo queda en propiedad de la revista y, por tanto, su publicación parcial y/o total en otro medio tiene que ser autorizado por el director de la Revista Explorador Digital.
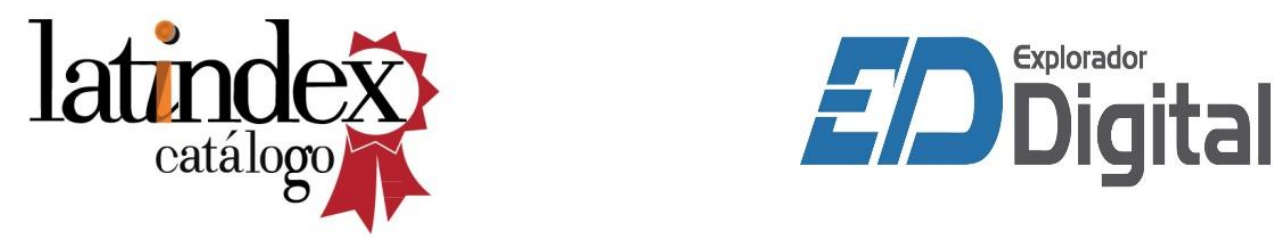